\title{
IRRUPCIÓN DE LA TEMÁTICA URBANA EN LA LITERATURA ARGENTINA
}

Guadalupe Isabel Carrillo Torea*

RESUMEN: El proceso de modernización de las ciudades latinoamericanas que se acentuó en las décadas de los cincuenta y sesenta se verá representado recurrentemente en la literatura, mostrando soluciones estéticas disímiles, cambiantes, en constante reorganización. Buenos Aires, como ciudad capital experimenta el fenómeno con rapidez delirante; su rostro urbano cambió radicalmente así como la manera de vivir la ciudad. Los intelectuales de la época se convierten en cronistas, creadores y testigos del ruido y el silencio de su ciudad.

Palabras clave: Ciudad, Literatura, Representación, Modernidad, Buenos Aires.

AвSTRACT: The process of modernization of the latinoamerican cities had emphasize about fifty and sixty decades, will see represent recurrent in literature, show solutions aesthetics dissimilar, changeable, in continuous reorganizacion. Buenos Aires, like capital city experiment the phenomenon whit velocity delirious; His urban face change radically like the way of life in the city. Intellectuals of that time be chronicler, creator and witness from noise and silence of the cities.

KEY WORDS: City, Literature, Representations, Modernity, Buenos Aires.

Lo urbano como tema en la literatura argentina y latinoamericana ha tenido una importancia tan radical que, más allá de constituirse en asunto, se asume como estilo y forma de ver el mundo o enfrentarlo. La evolución que sufrieron, fundamentalmente, las ciudades capitales de nuestro continente construyó al mismo tiempo un escenario de vida completamente distinto, con problemáticas e intereses personales y comunitarios diferentes.

* Centro de Investigación en Ciencias Sociales y Humanidades de la UAEm (gict@uaemex.mx). 
Es evidente que las manifestaciones artísticas mostrarían los cambios y darían voz a la inquietud que las ciudades grandes provocaban en sus habitantes. Dentro de ellas Buenos Aires se ha erigido en una de las más atrayentes tanto por su historia como por la belleza que, claramente, la viste. Escarbar en sus arrabales, en sus grandes avenidas o sus parques con árboles ancestrales traerá como consecuencia la creación de una literatura que evoca los espacios más recónditos de su ciudad para hacerlos presentes, darles vida y convertirlos en protagonistas. En las siguientes líneas se realiza un seguimiento de las obras más significativas de la literatura argentina en las que se entroniza a la ciudad capital, para observarla y vivirla.

\section{BuenOS AIRES: PASADO Y PRESENTE}

Buenos Aires, la ciudad portuaria que hoy en día está clasificada dentro de las “mega-ciudades”, vivió un proceso de crecimiento y urbanización desmesurado y extremadamente rápido. Según el antropólogo Hugo Gaggiotti, “entre 1870 y 1914 llegaron a la Argentina alrededor de seis millones de personas de las cuales aproximadamente la mitad se asentó en forma permanente[...] Entre 1895 y 1914 la población de la ciudad de Buenos Aires creció de 660000 habitantes al 1570000 habitantes”. ${ }^{1}$

El aumento desproporcionado de la densidad de población generó, evidentemente, un fuerte empuje en los trabajos de urbanización, aunque muchos de ellos eran el resultado de la improvisación y la falta de proyectos urbano-arquitectónicos adecuados. Los desajustes sociales no se hicieron esperar, así como el hacinamiento en los suburbios dentro de condiciones de vida absolutamente inapropiadas. Este fenómeno se daría de forma prácticamente paralela en muchos otros países del continente. Así lo afirma José Luis Romero en la obra Latinoamérica, las ciudades y las ideas, editada por primera vez en 1976. El autor señala que "En las primeras décadas del siglo xx se produjo en casi todos los países latinoamericanos, con distinta

${ }^{1}$ Hugo Gaggiotti, Scripta nova. Revista electrónica de Geografía y Ciencias Sociales, núms. 45(13), $1^{\circ}$ de agosto, 1999. 
intensidad, una explosión demográfica y social cuyos efectos no tardaron en advertirse”.2

A pesar de estos errores de cimientos en Buenos Aires, comenta Gaggiotti, la numerosa inmigración creará "las bases de un mundo urbano propicio para el desarrollo industrial” que irá dándose progresivamente con el correr de los años; muchos de ellos como producto del trabajo y la iniciativa de los mismos inmigrantes ya asentados en el país. Ante esta realidad que va desarrollándose, el tema urbano se convierte en lugar común dentro de aquellos escritores que apuestan por la expresión del mundo en el que habitan, y que igualmente será vista por muchos como sórdida, aniquiladora, pero también desbordante en su evolución hacia la modernidad.

\section{LO URBANO EN LA LITERATURA}

Por todo ello el tenor de la literatura urbana de las primeras décadas fluctúa entre el rechazo y la fascinación. El ejemplo de la obra de Roberto Arlt que, para la segunda década del siglo, toma a la ciudad como elemento protagónico diferente es ilustrativo. Arlt se detiene en la ciudad de los años treinta que está cambiando su fisonomía a pasos acelerados. Su impresión va de la mano de un sentimiento de terror y al mismo tiempo de atracción hacia ese mundo de la tecnología que empezaba a invadir los más cerrados arrabales porteños. Su discurso constituye una ruptura dentro de la tradición literaria que venía presentándose para entonces; la ciudad descrita y padecida es ahora no sólo la ciudad presente, sino la ciudad por venir, la del futuro problematizado por la novedad. A propósito de la obra arltiana Beatriz Sarlo puntualiza que

La ciudad y la técnica obsesionan la imaginación de Arlt: ambas lo empujan no sólo a ampliar un espacio temático, sino a construir una forma y un ideal de belleza. En el itinerario por la ciudad moderna, el escritor encuentra a la técnica;

2 José Luis Romero, Latinoamérica, las ciudades y las ideas, $6^{a}$ ed., México, Siglo XXI, 2001, p. 322. 
en su relación con la técnica aprende a ver una ciudad nueva para la literatura. Ciudad y técnica: no separadas sino unidas tanto en el movimiento de la ficción como en el impulso crítico, Arlt literalmente proyecta una ciudad porque, en sus textos, Buenos Aires es tanto una representación como una hipótesis. ${ }^{3}$

La ciudad, su ambiente y los elementos que la constituyen, está impregnada de una atmósfera destructiva que proviene de ese nuevo rostro adquirido a través de la presencia de lo moderno. Hombre y ciudad se convierten en una suerte de simbiosis en la que ambos se contaminan. Endorsain, personaje de Los lanzallamas experimenta esta fusión:

El tictac del reloj suena muy distante. Endorsain cierra los ojos. Lo van aislando del mundo sucesivas envolturas perpendiculares de silencio, que caen fuera de él, una tras otra, con tenue roce de suspiro [...] Ni siquiera percibe el latido de su corazón. Cuanto más, en el núcleo de aquella oscuridad que pesa sobre su frente distingue un agujerito abierto hacia los mástiles de un puerto distantísimo. Es única vereda de sol de una ciudad negra y distante, con graneros cilíndricos de cemento armado, vitrinas de cristales gruesos, y, aunque quiere detenerse, no se puede. Se desmorona vertiginosamente hacia una supercivilización espantosa: ciudades tremendas en cuyas terrazas cae el polvo de las estrellas, y en cuyos subsuelos, triples redes de ferrocarriles subterráneos superpuestos arrastran una humanidad pálida hacia un infinito progreso de mecanismos inútiles. ${ }^{4}$

Artl como escritor argentino se ocupa de la ciudad de Buenos Aires a la que ya incluye, desde un plural más generalizador, en las llamadas "ciudades tremendas” capaces de “arrastrar una humanidad pálida”.

El ejemplo de Arlt como la contra cara de lo que se había venido diciendo y viendo en la ciudad, marcha al unísono de la impresión que algunos intelectuales tuvieron, puesto que veían en la ciudad y en sus muchas sórdidas maneras una posibilidad de expresión igualmente válida, seductoramente llamativa. Es el periodo de principios de siglo donde encontraremos

3 Beatriz Sarlo, La imaginación técnica. Sueños modernos de la cultura argentina, Buenos Aires, Editorial Nueva Visión, 2004.

${ }^{4}$ Roberto Arlt, Los lanzallamas, 5a ed., Buenos Aires, Losada, 1999, p. 33. 
voces que prefiguran en el paisaje urbano la expresión alterna de un universo que se avecina impositivamente.

El antecedente principal de estas inclinaciones lo encontramos en la lírica. Cuando en 1909 Marinetti publica su Manifiesto Futurista y a propósito de la nueva estética declara que "Un automóvil en carrera con su caza ornada de tubos como serpientes de aliento explosivo[...], un automóvil rugiente que parece precipitarse contra la metralleta, es más hermoso que la Victoria de Samotracia”, 5 podemos entender, inequívocamente, que nos encontramos frente a una nueva estética de carácter exclusivamente urbano.

Las tendencias de las siguientes vanguardias —dadaísmo (1916) y surrealismo (1922) — aunque más abiertas a la diversidad, insisten en la alternativa de lo citadino como fuente principal de elaboración poética. De algún modo se vincula lo feo, o lo sórdido como elementos urbanos comunes. Esto, lejos de distanciar la atención de los intelectuales, los mantiene vinculados con el mundo de la ciudad, consignándoles una suerte de manera de repudio hacia la tradición, los convencionalismos, la cultura del poder. A propósito de estas consideraciones, Carlos Monsiváis en su obra Aires de Familia (2000) reitera que

La ciudad — trátese de La Habana o México o Buenos Aires o Caracas o Bogotá o Lima - es el tumulto de las anticipaciones. Su misma desmesura anuncia el derrumbe del control del tradicionalismo. Una profecía muy señalada del periodo 1880-1920 ve en las ciudades el espacio de las sensaciones inexploradas, ya no sólo el disolverse en la multitud como huida del control parroquial, ni las licencias que permite el consumo del alcohol, juego y prostitución, sino el aprendizaje de lo urbano como "naturaleza de relevo", el gusto por los paisajes insólitos, los cambios permanentes, las aglomeraciones, el encanto de la sordidez, las señas desastrosas del avance de la industria, la pérdida del sitio fijo que cada uno ocupaba en pueblos y pequeñas ciudades. ${ }^{6}$

${ }^{5}$ Nelson Osorio [encargado de la edición], Manifiestos, proclamas y polémicas de la vanguardia literaria hispanoamericana, Caracas, Biblioteca Ayacucho, 1988, p. 21.

${ }^{6}$ Carlos Monsiváis, Aires de familia. Cultura y sociedad en América Latina, Barcelona, Anagrama, 2000 (Col. Argumentos, 246), p. 207. 
Lo que Monsiváis apunta en las líneas anteriores describe de algún modo el progresivo fenómeno de secularización que se manifestó igualmente en el rostro de las ciudades. Si bien la construcción de monumentos pertenecientes a las instituciones que ostentaban el poder no se hicieron esperar, igualmente vemos que la llegada de la modernidad orientó los cambios arquitectónicos de las ciudades hacia la disparidad de estilos y, naturalmente, a la construcción de edificios más bien laicos e incluso profanos (casinos, prostíbulos, salas de baile...). Todo ello se verá reflejado igualmente en la literatura; de manera acuciante se presentó preferiblemente en el campo de la lírica, para trasladarse después al de la narrativa.

En esta tesitura encontraremos, para 1948, la publicación de la obra Adán Buenosayres de Marechal, en la que se representa la Buenos Aires de los años veinte. Rosalba Campra se refiere a ella como la ciudad del "espacio mítico", 7 es decir, aquella en la que el hombre desciende en busca de su yo. Se trata de un relato de carácter alegórico que se desenvuelve en los predios citadinos donde los vicios y los problemas de la argentinidad son representados a través de códigos urbanos. A propósito de la literatura argentina de los años cuarenta, Beatriz Sarlo en su obra Una modernidad periférica: Buenos Aires 1920 y 1930 (1988) resalta de qué manera la inmersión de las ciudades reales dentro del discurso literario es posible, en la medida en que se entienden como "espacios culturales". La escritora apunta:

Las orillas, el suburbio, son espacios efectivamente existentes en la topografía real de la ciudad y al mismo tiempo sólo pueden ingresar a la literatura cuando se los piensa como espacios culturales, cuando se les impone una forma a partir de cualidades no sólo estéticas sino también ideológicas. Se realiza, entonces, un triple movimiento: reconocer una referencia urbana, vincularla con valores, construirla con referencia literaria. En estas operaciones no sólo se compromete una visión "realista” del suburbio, sino una perspectiva desde donde mirarlo. ${ }^{8}$

${ }^{7}$ Rosalba Campra, América Latina. La identidad y la máscara, $2^{\mathrm{a}}$ ed., México, Siglo xxI, 1998, p. 56.

${ }^{8}$ Beatriz Sarlo, Una modernidad periférica. Buenos Aires. 1920 y1930, Buenos Aires, Nueva Visión, 1988, p. 180. 
La obra de Jorge Luis Borges no se puede dejar de lado. A Borges le interesaba el tema de la ciudad de manera especial. No olvidemos el comentario ya célebre de Carlos Fuentes en su ensayo La novela hispanoamericana (1969), en la que el escritor mexicano advierte categóricamente que "el primer narrador totalmente centrado en la ciudad, hijo de la urbe que corre por sus venas con palabras, rumores, silencios y orquestaciones de piedra, pavimento y vidrio, es Borges". ${ }^{9}$ Aunque Fuentes se refiera específicamente al Borges narrador, la lírica también tendrá como escenario y asunto central a la ciudad de Buenos Aires.

El sentido de la periferia y del suburbio al que refiere Beatriz Sarlo anteriormente es tema a tratar por el Borges lírico. Recordemos su libro Fervor de Buenos Aires publicado en 1923 donde las calles, las plazas, los barrios, el patio... son asunto de lo poético; en sus versos el yo poético de nuestro autor llega a decir: "Esta ciudad que yo creí mi pasado/ es mi porvenir, mi presente; / los años que he vivido en Europa son ilusorios,/ yo estaba siempre (estaré) en Buenos Aires". ${ }^{10}$ Pero la vinculación con su ciudad no puede interpretarse exclusivamente desde un sentimiento de nacionalismo; se trata más bien de filiación, de sentido de pertenencia en el que la ciudad se transforma en el tú cercano, presente, permanente, es el tú amado.

Años más tarde, en 1925, publicará el poemario La luna de enfrente, donde el tema citadino continúa —incluso con algún poema dedicado a la capital del Uruguay: "Montevideo"-; lo mismo podríamos decir de la obra Cuaderno de San Martín (1929), también poética, entre otras. Sin embargo, dado que la temática de esta investigación es el campo de la narrativa, me enfocaré a esta área fundamentalmente. De los innumerables cuentos que a lo largo de su vida escribiera Borges, la ciudad de Buenos Aires es escenario de muchos de ellos. Evidentemente, no se pretende ni enumerarlos ni rastrearlos exhaustivamente. Más bien, procuro interpretar y entender la visión que de la ciudad se proyecta y, sobre todo, el papel que desempeña en el argumento, en las estructuras mismas de algunos de los cuentos.

${ }^{9}$ Carlos Fuentes, La novela hispanoamericana, México, Joaquín Mortiz, 1969, p. 175.

10 Jorge Luis Borges, Obras completas, Buenos Aires, Emecé, 2000, p. 32. 
La línea general se sitúa en la presentación del Buenos Aires escenario, lugar en el que viven los compadritos, los inmigrantes ya argentinizados y orgullosos de su argentinidad. La ciudad es el espejo de sus nacionalismos, de la identidad que han ido forjando, bien sea que se sitúe en la periferia, en los suburbios o en el centro de la ciudad. El referente citadino está vinculado muchas veces con esa noción de la ciudad espacio-ingenuo que alberga individuos con horizontes reducidos a los límites de la misma. En su cuento El muerto del libro El Aleph (1949) el narrador nos dice: "Que un hombre del suburbio de Buenos Aires, que un triste compadrito sin más virtud que la infatuación del coraje, se interne en los desiertos ecuestres de la frontera del Brasil y llegue a capitán de contrabandistas, parece de antemano imposible."11 Efectivamente, en su generalidad, la voz del narrador asume una postura de una extraña conmiseración, con un aire de desdén hacia ese "triste compadrito”, habitante de los suburbios porteños. La mirada crítica no se deja esperar, de tal modo que la Buenos Aires borgeana espacio-ingenuo puede entenderse también como espacio marginal. Beatriz Sarlo, a propósito del paisaje urbano que Borges describe en sus primeros años, lo define como "el locus amenus de las orillas o los barrios". ${ }^{12}$ Este paisaje urbano idealizado, contrasta radicalmente con el percibido y descrito por Arlt en los mismos años.

Situándonos en la literatura argentina a través de las distintas décadas del siglo xx, se podrían establecer líneas generales de producción y temática en la que lo citadino va cobrando relevancia, aunque los matices que lo envuelven tienen especificidades de gran importancia que la definen de forma particular. En los años cuarenta por ejemplo, Buenos Aires recibirá masivas inmigraciones de españoles republicanos perseguidos por la dictadura franquista recién impuesta. Muchos de ellos crean empresas que darán un impulso considerablemente fuerte a la industria editorial; legalizan nuevas firmas que publicarán libros destinados a un público de masas que antes no era tomado en cuenta.

${ }^{11}$ Loc. cit.

12 Sarlo, Una modernidad... 
Frente a estas posibilidades los escritores de la época rescataron temáticas de carácter popular que dan un nuevo giro a la producción literaria. Se trata de la novela policíaca, que a pesar de su origen anglosajón, se desarrolla en los suburbios urbanos, tomando como protagonistas personajes propios de los arrabales de la gran ciudad, con matices más nacionalistas y propiamente porteños. Dentro de los más representativos estarían autores como "Borges y Bioy Casares (bajo el seudónimo de H. Bustos Domecq) publican Seis problemas para don Isidro Parodi en 1942; Leonardo Castellani (1899-1981), Las nueve muertes del padre Metri (1942) y Las muertes del Padre Metri (1952); Bioy Casares, El perjurio de la nieve (1944); Marco Deveni (1922), Rosaura a las diez (1955); Manuel Peirou, El estruendo de las rosas (1948)... entre otros”. ${ }^{13}$

\section{AÑOS CINCUENTA}

A mediados de los años cuarenta y ya entrando en los cincuenta la literatura fantástica se impondrá sobre cualquier otro género temático; sin embargo, no se excluirá de las narraciones fantásticas la contextualización urbana de Buenos Aires y el rescate de los habitantes de la urbe. Se ha hablado incluso de "el inicio de un fantástico cotidiano o fantástico costumbrista" en la obra de Bioy Casares fundamentalmente. Los escritores cercanos a la Revista Sur serán quienes fomenten en mayor medida este género. La advertencia última es necesaria debido a que escritores como Leopoldo Marechal y Ernesto Sábato, que publican a finales de la década del cuarenta, no siguieron el género fantástico.

Contrariamente su narrativa se centra en la búsqueda de nuevas técnicas narrativas - como es el caso concreto de Marechal- y escenarios urbanos más bien sórdidos. La concepción de la ciudad a través del filtro de lo alegórico, lo mítico o lo metafórico se hace presente en Sobre héroes y tumbas (1961) de Ernesto Sábato. El mundo de las cloacas en el que vive la secta de los ciegos es metáfora de lo que son estos ciegos y de la sordidez

${ }^{13}$ En http://www.todo-argentina.net/Literatura_argentina/los_años_cuarenta.htm. 
que los rodea. La ciudad destruye, acoge, impresiona por su grandeza y por sus contradicciones. El túnel, primera novela publicada por el autor en 1948, tiene como espacio de asentamiento para sus personajes la ciudad de Buenos Aires, aunque la fuerza temática de la obra se centra principalmente en el conflicto interior de su protagonista, con matices psicológicos y existenciales muy marcados.

En los años cincuenta la Argentina experimenta cambios políticos que convulsionan profundamente al país. El exilio de Perón y la caída de su régimen provocan un ambiente polémico e inseguro. Se trata, pues, de realidades ineludibles que serán expuestas en la producción literaria de la época a través del trabajo iniciado por la revista Contorno dirigida por Ismael Viñas y que tiene entre sus colaboradores a Noé Jitrik, León Rozitcher, Oscar Masotta, entre otros. ${ }^{14}$ La producción literaria de la época se aboca hacia un realismo experimentado desde la zozobra. Evidentemente el asunto urbano cobra vida como escenario ineludible, como espacio en conflicto por muchos factores externos que lo modifican inevitablemente. Se habla de autores como Bernardo Cordón con De ahora en adelante (1952) o Vagabundos en Tombuctú (1956); Bernardo Verbitsky con su obra Es difícil empezar a vivir (1941) o Café de los Angelitos y otros cuentos porteños (1950).

Los años sesenta estuvieron completamente inmersos en la renovación literaria que impulsó el fenómeno del boom. Las novedades técnicas fueron al unísono de una diversidad temática en la que se abordaban muy disímiles asuntos. Desde lo urbano capitalino, o lo urbano regional, pasando por la nueva incorporación de lo policíaco o el uso del folletín, el cine e igualmente la televisión. Para esto último la obra de Manuel Puig es paradigmática; La traición de Rita Hayworth (1968) da inicio a una serie de novelas en donde los medios masivos de comunicación cobran un protagonismo inédito; a través de él lo urbano se hace presente más que como paisaje, como temática nacida de la modernidad que a su vez se imprime en los mecanismos de comunicación, transformados en los recursos idóneos para establecer una nueva representación de lo real.

${ }^{14}$ En http://www.todo-argentina.net/Literatura_argentina/los_años_cincuenta.htm. 
Dentro de las novelas más transformadoras de la época Rayuela (1963) se erige entre las demás. Al margen de sus cualidades renovadoras en torno a elaboración de técnicas narrativas, a la construcción argumental y a la concepción misma de la obra en su totalidad, en Rayuela la ciudad, sea Buenos Aires o París, cobra relevancia, dejando a un lado la imagen de sordidez y hasta perversión que había adquirido en obras como Adán Buenos Aires de Marechal, para renovarse en una representación más cercana a su realidad extra-textual que se convierte en espacio de habitación ineludible.

Los acontecimientos históricos que envolvieron al país entre mediados de los años setenta y ochenta son tan relevantes que prácticamente toda la producción literaria se ve afectada, de raíz, por ellos. Nos referimos a la dictadura militar ocurrida entre 1976 y 1983 en la que las persecuciones, las desapariciones y, por supuesto, la autoridad militar se impuso de tal forma que transformó el modus operandi de sus habitantes, y de sus intelectuales muy en particular. Frente a una situación de fragmentación social y política tan severa, inevitablemente ésta se verá reflejada en la representación atomizada de lo real, que a su vez, modificará incluso las formas de expresión plasmadas a través del discurso.

De nueva cuenta la temática de lo represivo se impondrá cuestionando su pertinencia. Lo nacional prevalece asumiéndose desde la ética de la denuncia, del exilio forzado, del país invadido. La ciudad será pues el espacio problematizado donde sus protagonistas viven simbólica o realmente invasiones, pérdidas o desencuentros constantes. Andrés Rivera, David Viñas y Ricardo Piglia son algunos de los nombres más representativos de la época.

La narrativa actual no puede evadir la transformación de Buenos Aires como mega-ciudad y las dificultades que esto aporta a sus habitantes. Según los datos publicados por la onU, entre las diez urbes más pobladas para el año 2000, cuatro de ellas están en Latinoamérica: Sao Paulo, con 26 millones de habitantes, Río de Janeiro con 19 millones, Buenos Aires con 14 millones y ciudad de México con 21 millones de habitantes. Aunque no del todo exactos, los cálculos se han aproximado considerablemente a la realidad que vive la mayor parte de éstas. De nuevo José Luis Romero, acertada- 
mente comenta las consecuencias que la llamada “explosión urbana” ocasionó en Latinoamérica. El historiador puntualiza que

La explosión urbana modificó la fisonomía de las ciudades. Se quejaron de ello quienes las disfrutaron antes, apacibles y sosegadas, pero, sobre todo, con una infraestructura suficiente para el número de habitantes. Los invasores las desfiguraron e hicieron de ellas unos monstruos sociales que revistieron además, por los mismos años, los caracteres inhumanos que les prestó el desarrollo técnico. Alguien llegó a decir que las ciudades eran ya "invisibles". ${ }^{15}$

Esas ciudades invisibles de las que habla Romero son las "mega-ciudades" citadas en el párrafo anterior. Sus condiciones urbanas y la sobrepoblación de las mismas así lo certifican. Se trata, pues, de una suerte de despersonalización de la ciudad, de tal forma que pareciera que ésta desaparece, que se hace invisible, realmente, porque sus habitantes, a fuerza de ver sus calles, sus casas, dejan de ver su deterioro, la basura que las abarrota, las paredes pintarrajeadas y sucias. La sensación de dispersión, de caos, de pérdida de identidad en las "junglas urbanas" son algunas de las consecuencias de su descomunal crecimiento.

La literatura, como expresión artística que involucra directamente al hombre, dará cuenta de buena parte de las situaciones que viven los habitantes de las ciudades para enriquecer los matices que involucra la temática urbana, La experiencia del hombre citadino en el espacio urbano exige una posterior lectura y escritura del mismo en la que, probablemente, se re-fundará la ciudad. De ello dieron cuenta los escritores ya estudiados y seguirán haciéndolo en la actualidad todos aquellos que se ven inmersos en la ciudad como único territorio posible.

Recibido: agosto de 2007. Aceptado: septiembre de 2007.

${ }^{15}$ Romero, op. cit. 
BIBLIOGRAFÍA

Arlt, RoBerto, Los Lanzallamas, 5a ed., Buenos Aires, Losada, 1999, 340 pp.

Borges, Jorge LuIs, Obras completas, Buenos Aires, Emecé, 2000, 514 pp.

Campra, Rosalba, América Latina. La identidad y la máscara, $2^{\mathrm{a}}$ ed., México, Siglo Xxi, 1998, 214 pp.

Fuentes, CARLOS, La novela hispanoamericana, México, Joaquín Mortiz, 1969.

Monsiváis, Carlos, Aires de familia. Cultura y sociedad en América Latina, Barcelona, Anagrama, 2000, 240 pp. (Col. Argumentos, 246).

Romero, José Luis, Latinoamérica. Las ciudades y las ideas, $6^{\mathrm{a}}$ ed., México, Siglo XXI, 2001, 204 pp.

SARLO, BEATRIZ, La imaginación técnica. Sueños modernos de la cultura argentina, Buenos Aires, Nueva Visión, 2004, 210 pp. 
